\title{
Numerical investigation of a pair of self-propelled AUVs operating in tandem
}

\author{
Pareecha Rattanasiri ${ }^{\mathrm{a}, *}$, Philip A. Wilson ${ }^{\mathrm{b}}$, Alexander B. Phillips ${ }^{\mathrm{b}}$ \\ ${ }^{a}$ Department of Mechanical Engineering, Faculty of Engineering, Burapha University, \\ Chonburi, Thailand. 20131 \\ ${ }^{b}$ Fluid Structure Interactions Group, Faculty of Engineering and the Environment, \\ University of Southampton, Southampton \\ United Kingdom SO16 7QF
}

\begin{abstract}
This paper investigates the influence of the propeller race on upstream and downstream self-propelled AUVs. Initially simulations of a self-propelled hull are performed at the Reynolds Number $3.2 \times 10^{6}$ with the commercial RANS code ANSYS CFX 12.1, utilising a body force model to replicate the impact of the propeller utilising momentum source terms. This is then extended to consider a fleet of two self-propelled vehicles operating at a range of longitudinal offset and transverse separations. The results highlight that operation in close proximity to another self-propelled vessel has a significant impact of both the flow around the hull and drag experienced by the vehicle. A propeller race deduction is proposed to account for the increase in vehicle drag due to the propulsors of other vehicles. The propeller race deduction is dependent upon both longitudinal and transverse separation. From a vehicle or mission design perspective, it is important to correctly understand the true propulsive energy budget of the vehicle and its impact on both range and endurance. This study highlights the importance of considering both thrust deduction and any propeller race deductions when calculating the propulsive power consumption of an individual or fleet of vehicles.
\end{abstract}

Keywords: co-operative AUVs, drag, RANS-SST, self-propelled model, body force model, propeller race deduction

\section{Introduction}

The rapid growth in ocean operational services such as: offshore engineering, defence, shipping and marine ecosystem survey, challenge the performance and efficiency of manned and unmanned robotic systems (Woods, 1997). Since cold and deep ocean operational conditions are deemed too dangerous or impractical for humans (Caccia, 2006; Horgan and Toal, 2006; Smallwood and Whitcomb, 2004), unmanned submersibles are typically employed. Autonomous Underwater Vehicles (AUVs) are self-propelled robots which perform missions without requiring external powering or control. They are a cost-effective alternative compared to many current manned and tethered system, AUVs are becoming widely used to assist existing ocean science and engineering operations. Current AUVs are primarily designed to perform as a solo vehicle for specific missions, typically inspection or exploration tasks with an operational range up to one thousand kilometres and mission durations ranging from numbers of hours to several days.

The operational ability of an AUV depends on the required speed, range, depth, duration and manoeuvring performance of the vehicle. Since the range and endurance are limited by the cruise speed (Bingham et al., 2002; Furlong et al., 2007; McPhail, 2009; Stevenson et al,, 2007; Tripp, 2006), the options to extend an endurance are: minimising drag (Huggins and Packwood, 1994; Parsons, 1972; Parsons et al., 1974), enhancing propulsive efficiency (Ageev, 2000, 1995; Stevenson et al., 2007), increasing specific energy of power sources (Ageev, 2000; Alers, 1981), and reducing hotel load (Furlong et al., 2007; Phillips et al., 2012).

Many simple observations suggest that the drag of an individual may be reduced in specific fleet configurations: examples such as, birds form an echelon formation for long distance migration (Andersson and Wallander, 2003), fish swim in shoals or schools (Alexander, 2004; Hanrahan and Juanes, 2001; Partridge et al., 1983). There are energy benefit to slipstreaming while cycling (Kyle, 1979), driving in convoy (Hucho and Ahmed, 1998) or swimming (Silva et al., 2008). There is a 60\% energy saving for bottlenose dolphin calves when swimming in close proximity to their mothers (Weihs, 2004). Recent studies have also demonstrated energy savings for fleets of towed

\footnotetext{
*Corresponding author

Email addresses: pareecha@eng.buu.ac.th (Pareecha Rattanasiri), philip.wilson@soton.ac.uk (Philip A. Wilson), abp@soton.ac.uk (Alexander B. Phillips)
} 
generic AUV hull forms at specific longitudinal and transverse offsets (Husaini et al., 2009; Rattanasiri et al., 2014). However, the propeller's influence has been excluded from these simulations. Axial and tangential accelerations, applied to fluid by the action of the propeller, lead to significant variations in the flow field around the stern of the vessel and downstream, see Figure 1

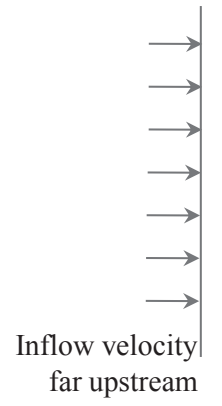

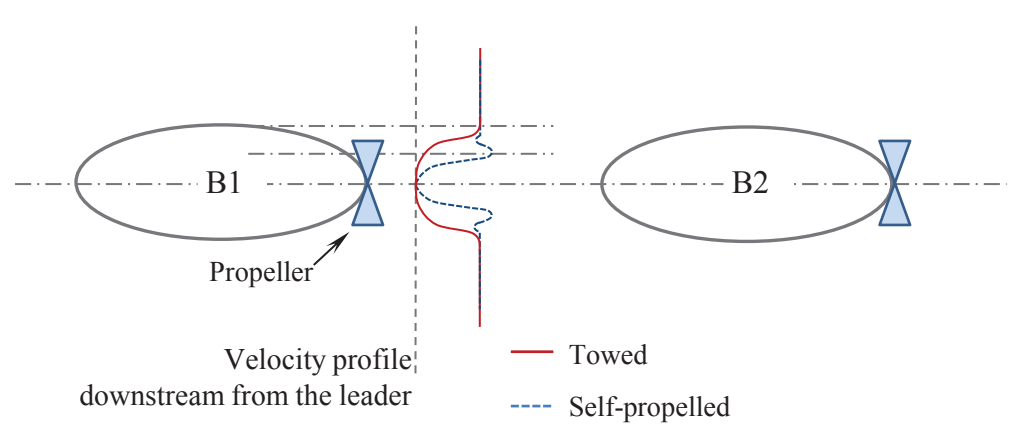

Figure 1: Velocity profile of fluid inflow past AUVs, B1 and B2 represents the leader and follower AUV, respectively.

Firstly, the accelerated flow due to the propeller results in increased skin friction resistance at the stern, as well as reduced local pressures which increase the form drag of the self-propelled body. For an AUV to move forward at the design speed, the required thrust, $T_{S P}$, must typically exceed its total towed drag, $R$, (Burcher and Rydill, 1994):-

$$
T_{S P}=\frac{R}{1-t}
$$

where $R$ is the towed drag of the bare hull and propeller and $t$ is defined as the thrust deduction which is a function of hull streamlining, propeller clearance and fullness (Burcher and Rydill, 1994).

Secondly, the propeller race from upstream or adjacent vessels will modify the flow field of nearby vehicles. For example a vehicle placed directly downstream of the propeller of an upstream vehicle will experience additional axial and tangential flow velocities in comparison to towed wake conditions, in this study, the increase in thrust required due to the propeller race from nearby vehicles is defined as a propeller race deduction, $\gamma$,

$$
T_{S P}=\frac{R}{1-t-\gamma} .
$$

Investigation of self-propelled fleet configurations will provide more information on the true propulsive energy budget of a fleet of AUVs. The generated wake upstream/downstream could lead to a reducing/raising energy consumption, this leads to the underlying questions of:-

- does the impact of propeller provide the energy advantages/disadvantages to the fleet configuration?

- does a fleet configuration provide energy benefits for just an individual AUV or the whole fleet?

- what is the optimal configuration and optimal distances of the fleet?

The purpose of this paper is to provide guidance for operators on suitable spacing for multiple vehicles' missions. To achieve this aim, the two hydrodynamic processes of twin self-propelled AUVs: the body-to-body interference (or viscous interaction) and the increase of drag due to re-energised wake by a self-propelled vehicle must be numerically investigated.

\section{Theoretical approach}

Prediction of the hydrodynamic force acting on an AUV's hull can be modelled using a steady-state Reynolds Averaged Navier Stokes (RANS) simulation. This has proved to provide reasonably accurate results with modest computational cost (Jagadeesh et al., 2009; Karim et al., 2009; Phillips et al., 2008, 2007, 2010c; Sarkar et al., 1997). The commercial RANS solver ANSYS CFX 12.1 (ANSYS, 2010) is selected to perform in this study. By assuming the flow is incompressible, the continuity equation in tensor notation becomes:-

$$
\frac{\overline{\partial U_{i}}}{\partial x_{i}}=0
$$


The momentum equation can be written as:-

$$
\rho\left(\frac{\partial \overline{U_{i}}}{\partial t}+\frac{\partial \overline{U_{i} U_{j}}}{\partial x_{j}}\right)=-\frac{\partial \bar{P}}{\partial x_{i}}+\frac{\partial}{\partial x_{j}}\left\{\mu\left(\frac{\partial \overline{U_{i}}}{\partial x_{j}}+\frac{\partial \overline{U_{j}}}{\partial x_{i}}\right)\right\}-\rho \frac{\partial \overline{u_{i}^{\prime} u_{j}^{\prime}}}{\partial x_{j}}+\bar{F}_{i}
$$

where the tensor $x_{i}$ represents Cartesian co-ordinates $(X, Y, Z)$ and $U_{i}$ are the Cartesian mean velocity components $\left(\overline{U_{x}}, \overline{U_{y}}, \overline{U_{z}}\right)$. The Reynolds stress tensor $\left(\overline{\rho u_{i}^{\prime} u_{j}^{\prime}}\right)$ is represented by the turbulence closure. $\bar{F}_{i}$ represents additional momentum source terms $\left(\bar{F}_{X}, \bar{F}_{Y}, \bar{F}_{Z}\right)$.

The shear stress transport (SST) turbulence closure model (Menter, 1994) which blends $k-\varepsilon$ and $k-\omega$ was selected for this study. Previous investigations have shown that it is better able to replicate the flow around the ship and submarine hull forms than either $k-\varepsilon$ or $k-\omega$ model, notably with a moderate computational cost (Larsson and Baba, 1996; Phillips et al., 2010b).

The flow around a rotating propeller is a complex transient flow, high mesh resolution is required around the blade in order to resolve the flow features. Small time steps are required to capture the transient flow behaviour. The problem considered in this paper does not concentrate on the propeller, but rather on a representative model of the velocity field downstream of the propeller. Therefore, this work utilises a body force approach proposed for self-propelled ship simulations. When using a body force model, the geometry of the propeller is not explicitly represented. The effect of the propeller on the flow is modelled for $\bar{F}_{i}$ as distributed axial and tangential momentum source terms which induce axial and swirl accelerations in the fluid. The considered model prescribes a radial distribution of thrust and torque based on the Hough and Ordway (1965) circulation distribution, which has zero loading at the tip and root was shown to match Goldstein's optimum distribution (Goldstein, 1929). Coupling this distribution with a RANS simulation has been implemented by Paterson et al. (2003); Phillips et al. (2008, 2010a); Phillips (2009); Stern et al. (1988); Turnock et al. (2008). The non-dimensional thrust distribution $\left(F \bar{b}_{x}^{\prime}\right)$ and the non-dimensional torque distribution $\left(\bar{F} \bar{b}_{\theta}^{\prime}\right)$ are given by:-

$$
\begin{aligned}
& F \bar{b}_{x}^{\prime}=A_{x} r^{*} \sqrt{1-r^{*}} \\
& F \bar{b}_{\theta}^{\prime}=A_{\theta} \frac{r^{*} \sqrt{1-r^{*}}}{\left(1-Y_{h}\right) r^{*}+Y_{h}}
\end{aligned}
$$

where:

$$
\begin{aligned}
& A_{x}=\frac{C_{t h}}{\Delta x} \frac{105}{16\left(4+3 Y_{h}\right)\left(1-Y_{h}\right)} \\
& C_{t h}=\frac{8 K_{T}}{\pi J^{2}}=\frac{2 T}{\rho V_{a}^{2} \pi R_{p}^{2}} \\
& A_{\theta}=\frac{K_{Q}}{\Delta x J^{2}} \frac{105}{\pi\left(4+3 Y_{h}\right)\left(1-Y_{h}\right)} \\
& J=\frac{V_{a}}{n\left(2 R_{p}\right)} \\
& V_{a}=\frac{\left(1-w_{t}\right)}{V}
\end{aligned}
$$

where: both $C_{t h}$ and $K_{T}$ are the thrust coefficient with different form as shown in Euaqtion $8 K_{Q}$ is the torque coefficient. $J$ is the advance coefficient, $T$ is the thrust, $w_{t}$ is the wake fraction, $n$ is the revolutions per second, $V$ is the vehicle speed and $V_{a}$ is the advance speed. The momentum source terms are then applied to an annulus with finite thickness $(\Delta x)$ defined by:-

$$
Y_{h}=\frac{R_{h}}{R_{p}}, Y=\frac{r_{p}}{R_{p}}, \quad r^{*}=\frac{Y-Y_{h}}{1-Y_{h}}
$$

where $R_{p}$ and $R_{h}$ are the radius of propller and hub, respectively. $r_{p}$ is the local propeller radius. See Figure 2 for detail. 


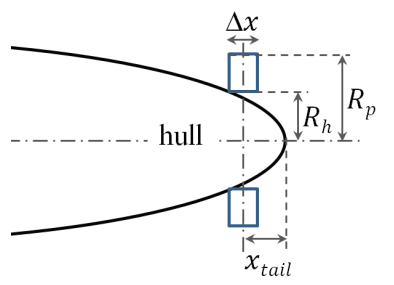

Figure 2: Body force propeller model

\section{Case study}

\subsection{Assumed hull shape}

A shape of a 6:1 prolate spheroid with a length $(L)$ of $1200 \mathrm{~mm}$ and a diameter of $200 \mathrm{~mm}$, is assumed to represent the AUV hull shape, giving a surface area $\left(A_{w}\right)$ of $0.601 \mathrm{~m}^{2}$. This investigation neglects the effect of appendages and other protrusions through the hull. Previously a series of wind tunnel experiments were performed on the flow past twin prolate spheroids of this shape to characterise the side-force and yawing moment interactions at different transverse spacings (Molland and Utama, 1997). Tests were carried out in the 7' $\times 5^{\prime}(2.20 \mathrm{~m} \times 1.57 \mathrm{~m})$ low speed wind tunnel at the University of Southampton. The top spheroid (B1) was placed at the middle breadth and $1.07 \mathrm{~m}$ height from the floor. The lower spheroid (B2) was placed at the transverse separation $(S / L)$ of 0.27 , 0.37 and 0.47 away from the centreline of B1. The noses of both spheroids are aligned with zero longitudinal offset $(D / L=0)$ as shown in Figure 3 .

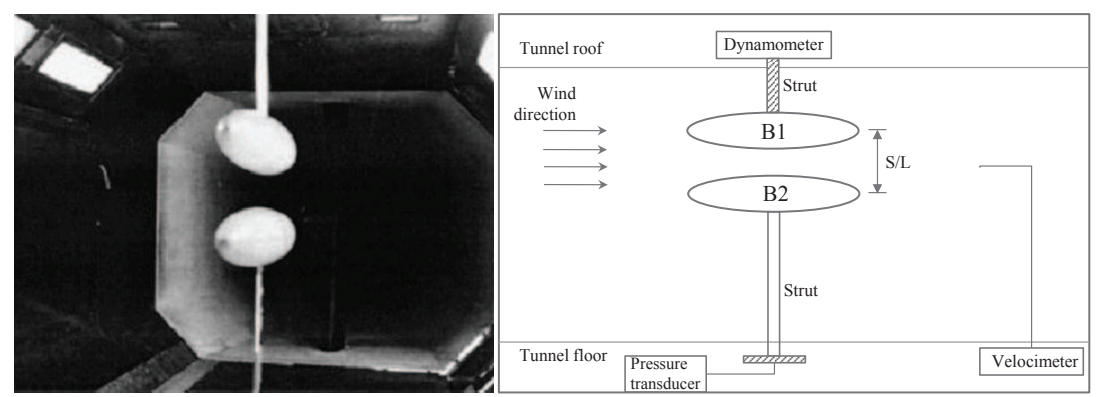

Figure 3: Twin prolate spheroids in the $14 \mathrm{~m}$ long, $7^{\prime} \times 5^{\prime}$ wind tunnel, figure adapted from Molland and Utama 1997)

\subsection{Assumed propeller characteristics}

The propeller performance is scaled from Autosub3 (Griffiths, 2003), the ratio of propeller diameter to maximum hull diameter is 0.8 . The $K_{T}$ and $K_{Q}$ of Autosub3 related to $J$ is predicted by the following equations (Phillips et al., 2009):-

$$
\begin{aligned}
& K_{T}=0.5106 J^{3}-0.7700 J^{2}+0.2017 J+0.0529 \\
& 10 K_{Q}=0.3920 J^{3}-0.7499 J^{2}+0.3218 J+0.0032
\end{aligned}
$$

For numerical stability, the ratio of finite length of the propeller disc and maximum diameter of the disc is suggested to be $\geq 0.1$ (Phillips et al., 2010a). The other parameters are in the Table1.

Table 1: Parameter of modelled propeller

\begin{tabular}{|c|c|c|c|c|}
\hline Parameters & $R_{p}(\mathrm{~m})$ & $R_{h}(\mathrm{~m})$ & $\Delta x(\mathrm{~m})$ & $x_{\text {tail }}(\mathrm{m})$ \\
\hline Setting & 0.080 & 0.0154 & 0.0154 & 0.007 \\
\hline
\end{tabular}

In this study, the propeller rpm is iteratively varied to determine the appropriate advance coefficient (Equation 107, thrust coefficient (Equation 13) and torque coefficient (Equation 14) to achieve self-propulsion. 


\subsection{Present study}

The configuration of a pair of AUVs is shown in Figure 4 where $S / L$ is the transverse separation and $D / L$ is the longitudinal offset, B1 and B2 represents the leader and follower, respectively. The action of the propeller is to re-energise the wake compared to a towed vessel. This propeller race will interact with any vehicles directly downstream impacting on their own drag. The propeller test case matrix in this study is shown in Table 2

- Initial simulations are performed for a single hull. Case S1 is the benchmark towed single hull. Case S2 corresponds to a self-propelled vehicle where the resulting is modelled and torque is neglected. Case S3 corresponds to a self-propelled vehicle modelling thrust and torque. Comparing S2 and S3, the influence of the propeller torque and swirling flow may be examined.

- Subsequently, simulations are performed for a fleet of two vehicles. Cases F1 to F6 examine a fleet performance for various combinations of the towed and self-propelled vehicles at $S / L=0$ and $D / L=1.47$.

- The impact of spacing on drag, thrust deduction and the propeller race deduction of a pair of self-propelled vehicles is then investigated by setting up Case F6 with varying $1.17 \leq D / L \leq 1.77$ and $0.0 \leq S / L \leq 0.37$.

- Cases F1 to F3 are then extended to consider in detail; two self-propelled vehicles at a selection of longitudinal offsets for $1.17 \leq D / L \leq 4.47$ and transverse separations for $0.17 \leq S / L \leq 0.47$.

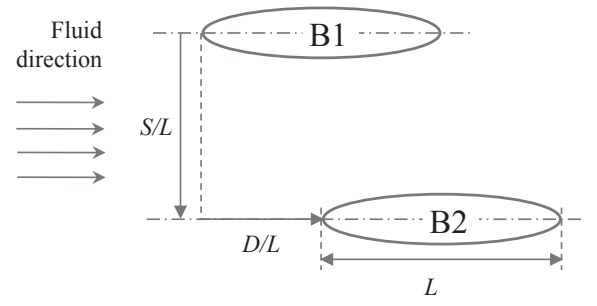

Figure 4: A pair of prolate spheroids in fleet configurations. Where $S / L$ is the transverse separation and $D / L$ is the longitudinal offset, B1 and B2 represents the leader and follower AUV, respectively.

Table 2: Propeller test case matrix to simulate twin self-propelled vehicles in $S / L=0$ and $D / L=1.47$ configuration at various propulsive conditions.

\begin{tabular}{|c|c|c|}
\hline Case & B1 & B2 \\
\hline S1 & Towed Hull & - \\
S2 & Thrust Only Propeller Model & - \\
S3 & Thrust and Torque Propeller Model & Towed Hull \\
F1 & Towed Hull & Towed Hull \\
F2 & Thrust Only Propeller Model & Thrust Only Propeller Model \\
F3 & Thrust Only Propeller Model & Towed Hull \\
F4 & Thrust and Torque Propeller Model & Thrust Only Propeller Model \\
F5 & Thrust and Torque Propeller Model & Thrust and Torque Propeller Model \\
F6 & Thrust and Torque Propeller Model & Thr \\
\hline
\end{tabular}

\subsection{Numerical settings and mesh strategy}

The fluid domain is modelled as $1.4 L \times 12 L \times 1.8 L$ to replicate the experimental domain of Molland and Utama (1997). Both hulls are modelled using a no slip wall condition. A free slip wall condition is used for the roof, floor and walls. The simulation is performed at a length Reynolds number $(R e)$ of $3.2 \times 10^{6}$ (Typical AUV operation occurs at $\left.10^{5}<R e<10^{7}\right)$ corresponding to an air inlet velocity $(V)$ of $40 \mathrm{~m} / \mathrm{s}$. The outlet is set at zero relative pressure. The air density $\left(\rho_{\text {air }}\right)$ and the air kinematic viscosity $\left(v_{\text {air }}\right)$ at room temperature are $1.185 \mathrm{~kg} / \mathrm{m}^{3}$ and $1.545 \times 10^{-5} \mathrm{~m}^{2} / \mathrm{s}$, respectively. The computational parameters are provided in Table 3 . Figure $5 \mathrm{a}$ and $5 \mathrm{~b}$ show the sample of meshes cut in the $Z X$ plane and the $Y Z$ plane, respectively. Figure 6 shows the influence on mesh size on the drag of a towed spheroid, eleven meshes where built ranging from 1.2 to 22.7 million elements. The 
computational cost of using the medium mesh (8.9 million elements) is 10 times lower then that of the fine mesh (22.7 million elements) with a less than $2 \%$ variation in drag. Details of the fluid domain discretisation and mesh strategy's validation is completely presented in Rattanasiri et al. (2014). Results utilising these meshes exhibited good correlation with the pressure distribution, the side-force coefficient, form factor and the towed drag measured in: the wind tunnel experiments (Molland and Utama, 1997), previous numerical analysis (Molland and Utama, 2002) and empirical predictions (Hoerner, 1965). By implementing a propeller model, the investigation of the impact of propellers to a fleet of self-propelled twin hulls can be performed.

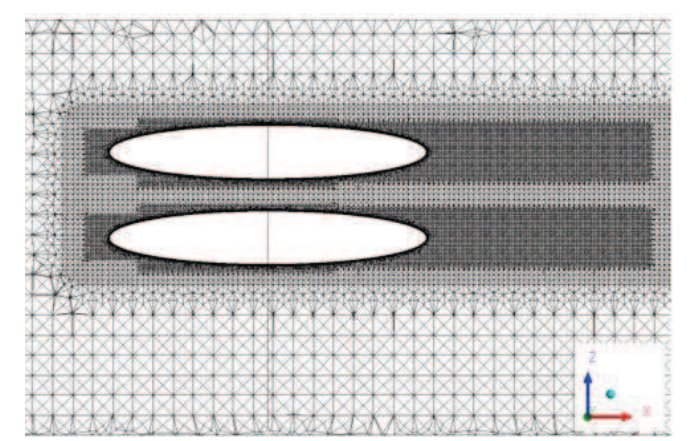

(a) $Z X$ plane at the centre line at $Y=0$ with the fluid flow from left to right

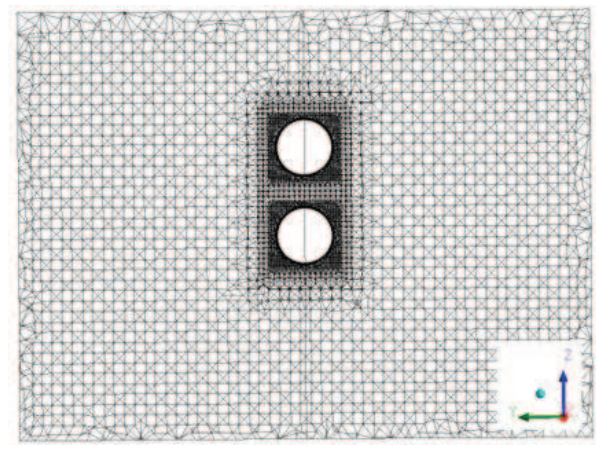

(b) $Y Z$ plane at $X=0.6 \mathrm{~m}$ from the noses

Figure 5: Mesh cut around a pair of spheroids for $S / L=0.27$ and $D / L=0$

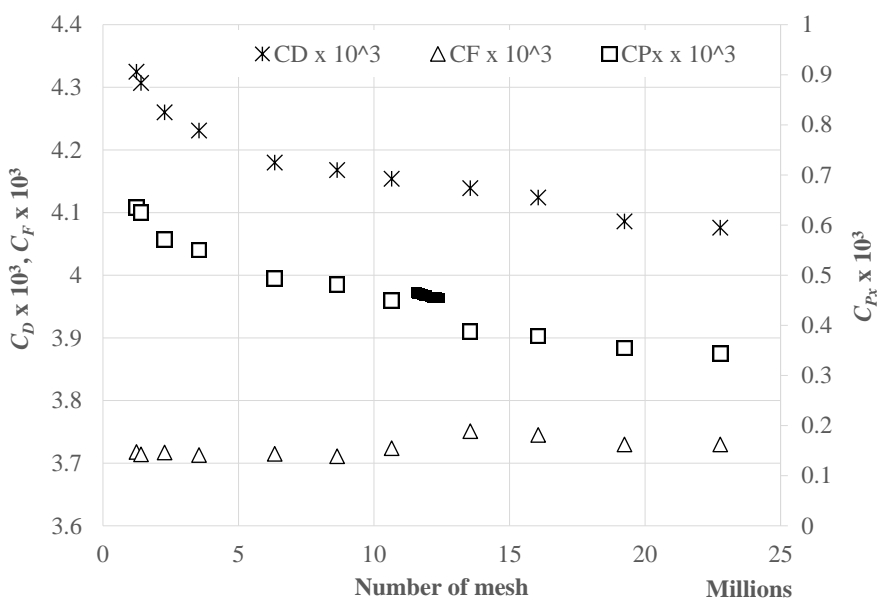

Figure 6: Mesh convergence of a pair of spheroids 
Table 3: Computational parameters

\begin{tabular}{|l|l|}
\hline Parameters & Setting \\
\hline Global mesh size & $0.20 \mathrm{~m}$ \\
Mesh type & Unstructured with local \\
& $\begin{array}{l}\text { refinement around spheroids } \\
\text { and in wake regions }\end{array}$ \\
& 30 \\
$y^{+}$average & $8-15 \mathrm{M}$ with 15 prism layers \\
No. of elements & in the boundary layer \\
& Shear Stress Transport \\
Turbulence model & $1 \%$ \\
Inlet turbulent intensity & Automatic Wall Function (ANSYS, 2010) \\
Wall modelling & High Resolution (ANSYS, 2010) \\
Spatial discretisation & Auto Timescale (ANSYS, 2010) \\
Timescale control & RMS residual < 10-6 \\
Convergence criteria & IRIDIS 3 Linux Cluster \\
Computing & Parallel (12 partitions run on \\
Run type & $4 \times$ Dual core nodes, \\
& each with 2GB RAM) \\
Simulation Time & $2.0-2.5$ wall clock hours \\
\hline
\end{tabular}




\section{Results}

\subsection{Single vehicle}

Table 4 details the thrust deduction calculated for a single hull. The propeller revolution speed of each selfpropelled AUV is iterated until the error between the self-propelled thrust $\left(T_{S P}\right)$ and the self-propelled drag $\left(T_{D}\right)$ are within $2 \%$. Assuming no swirl is imparted to the flow $\left(K_{Q}=0\right)$ results in a predicted thrust deduction of $t=0.13$. Inclusion of a representative torque results in a prediction of $t=0.14$. The numerical predictions of thrust deduction $(t)$ are within the ranges suggested in Burcher's experiment (Burcher and Rydill, 1994).

Table 5 shows a breakdown of the pressure and skin friction components of the drag for cases S1, S2 and S3. The thrust deduction is driven by a change to the pressure drag. Figure 7 shows an accelerated flow regime behind the propeller plane B1. These cases demonstrate the importance of considering the self-propelled drag when assessing total energy budget of an AUV.

Table 4: Thrust deduction and drag results of a single towed hull and a single self-propelled AUV with two different propulsive conditions

\begin{tabular}{|c|c|c|c|c|}
\hline Body Force Model & $\begin{array}{c}\text { Towed drag, } \\
R(\mathrm{~N})\end{array}$ & $\begin{array}{c}\text { Self-propelled } \\
\text { thrust, } T_{S P}(\mathrm{~N})\end{array}$ & $\begin{array}{c}\text { Self-propelled } \\
\text { drag, } T_{D}(\mathrm{~N})\end{array}$ & $\begin{array}{c}\text { Thrust } \\
\text { deduction, } t\end{array}$ \\
\hline S1: Towed hull (No propeller model) & 2.3014 & - & - & - \\
\hline S2: Thrust Only Propeller & - & 2.6393 & 2.6426 & 0.13 \\
\hline S3: Thrust and Torque Propeller & - & 2.6830 & 2.6874 & 0.14 \\
\hline
\end{tabular}

Table 5: Drag coefficient of a single towed hull and a single self-propelled AUV at two different propulsive conditions. Define the percent drag difference compare to case $\mathrm{S} 1$ as $\% \Delta_{t o} S 1=\frac{\operatorname{drag}_{i}-\operatorname{drag}_{(S 1)}}{\operatorname{drag}_{(S 1)}}$, where $i$ represents cases S2 and S3

\begin{tabular}{|c|c|c|c|c|c|c|}
\hline Cases & $\begin{array}{c}\text { Total drag } \\
\text { coef. } \\
C_{D} \times 10^{3}\end{array}$ & $\% \Delta_{(S 1)}$ & $\begin{array}{c}\text { Skin friction } \\
\text { drag coef. } \\
C_{F} \times 10^{3}\end{array}$ & $\% \Delta_{(S 1)}$ & $\begin{array}{c}\text { Pressure } \\
\text { drag coef. } \\
C_{P x} \times 10^{3}\end{array}$ & $\% \Delta_{(S 1)}$ \\
\hline S1: Towed hull & 4.053 & - & 3.643 & - & 0.347 & - \\
\hline S2: Thrust Only Propeller & 4.632 & 14.7 & 3.647 & 0.1 & 1.012 & 191.6 \\
\hline S3: Thrust and Torque Propeller & 4.709 & 16.6 & 3.648 & 0.1 & 1.089 & 213.8 \\
\hline
\end{tabular}

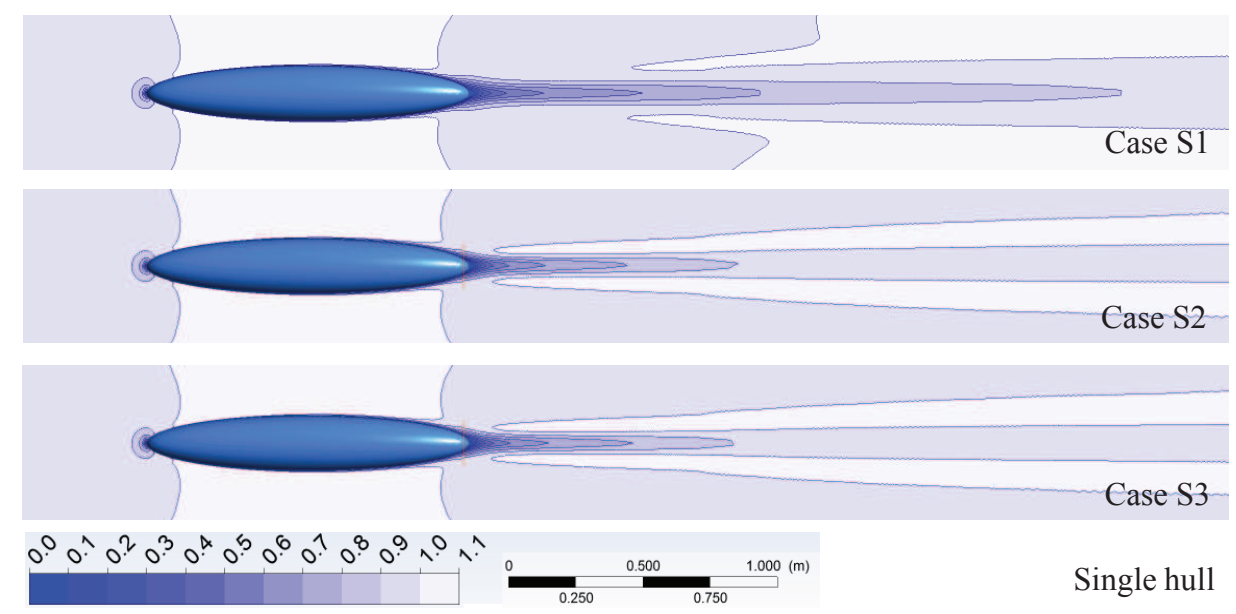

Figure 7: Comparison of velocity profile $V / V_{\infty}$ of fluid inflow past a single AUV; (Top) Case S1: Towed hull, (Middle) Case S2: Self-propelled AUV by thrust only propeller and (bottom) Case S3: Self-propelled AUV by thrust and torque propeller.

\subsection{Velocity profile of drafting twin vehicles at $D / L=1.47$}

The flow velocity past two drafting hulls $(S / L=0$ and $D / L=1.47)$ is demonstrated in Figure 8 . Three cases are shown:

- case F1 where both hulls are towed (dotted line) 
- case F2 where the leader B1 is the self-propelled vehicle and the follower B2 is towed (dashed line)

- case F3 where both vehicles are self-propelled (continuous line)

From a uniform inflow $(D / L=-1.250)$, the boundary layer develops over B1 $(0<D / L<1.0)$. At the propeller plane of $\mathrm{B} 1(D / L=0.994)$, a difference may be observed between cases $\mathrm{F} 1$ and $\mathrm{F} 2 \& \mathrm{~F} 3$. For the towed case, $\mathrm{F} 1$, the advance velocity at the propeller plane is lower than the free-stream velocity due to the presence of the boundary layer the reduction in local velocity corresponds to a mean wake fraction $\left(\bar{w}_{t}\right)$ of 0.148 (calculated by Equation 11). Cases F2 and F3 experience an increase in the axial momentum on the propeller plane of B1, which is due to the action of the propeller. This axial increment increases with the slipstream contraction at $D / L=1.235$.

The inflow to $\mathrm{B} 2(D / L=1.470)$ differs for the towed B1 $(\mathrm{F} 1)$ where there is a wake deficit and the selfpropelled B1 (F2\&F3) where the propeller race has re-energised the wake, however, this is a non-uniform inflow. For all cases the boundary layer then develops around B2 at $1.470<D / L<2.463$. At the propeller plane of B2 $(D / L=2.463)$, the mean wake fraction for B2 for case $\mathrm{F} 2$ is 0.143 .

Downstream at $D / L=4.789$, the three cases show different behaviour where F1 exhibits the largest wake deficit, F3 the smallest. Case F1 exhibits a wake deficit due to both vehicles' drag, F2 exhibits a wake deficit due to B2's drag and the re-energised wake of the propeller 1, and F3 exhibits a nearly completely uniform flow since both vehicles are self-propelled.
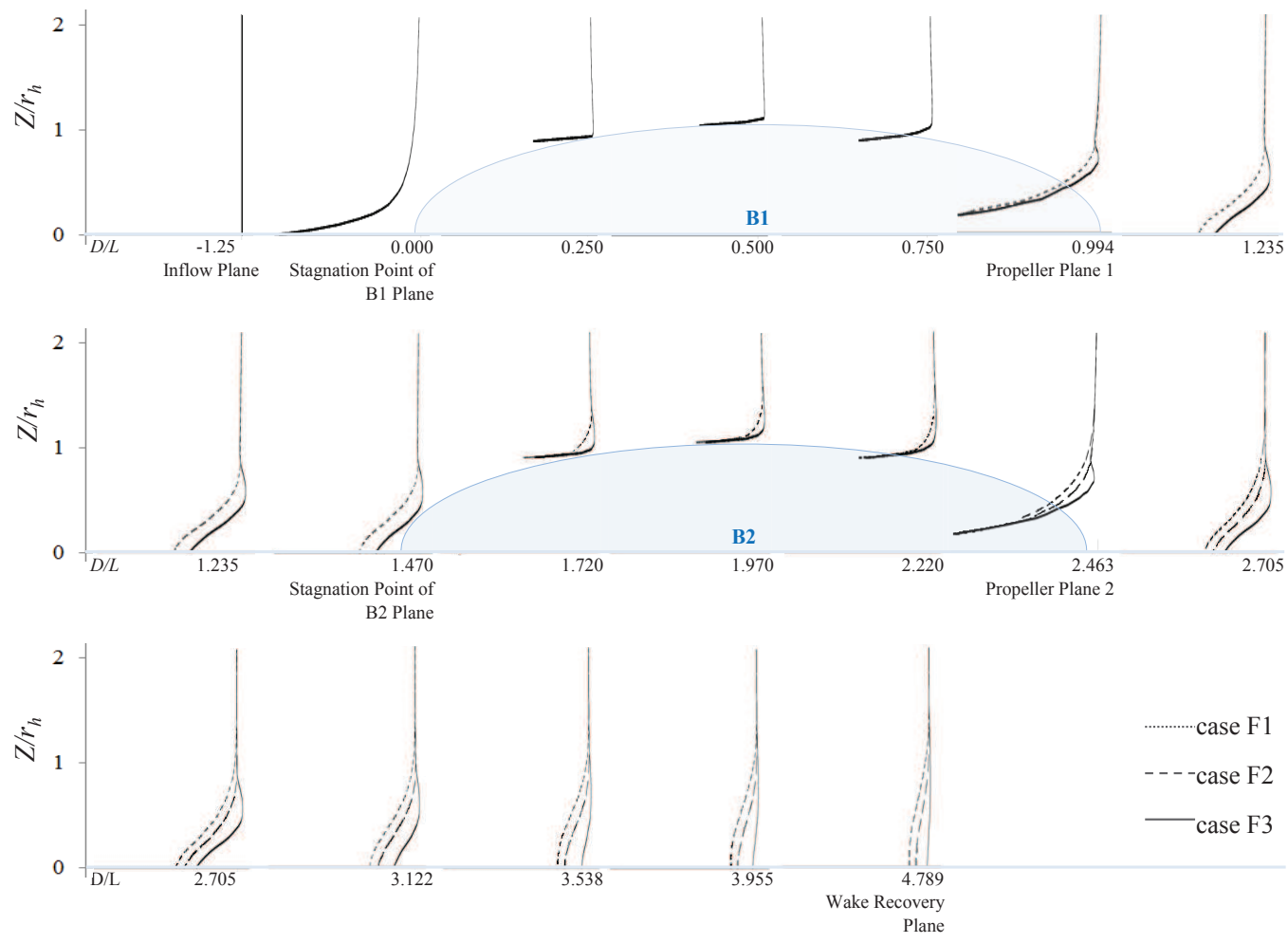

Figure 8: The velocity profile of the flow past two in-line hulls $(S / L=0, D / L=1.47)$. case F1 where both hulls are towed (dotted line), case F2 where the leader (B1) is the self-propelled vehicle and the follower (B2) is towed (dashed line), and a final case F3 where both vehicles are self-propelled (continuous line)

The influence of the propeller model on the self-propelled drag, the thrust deduction and the propeller race deduction are demonstrated in Figure 9 for a longitudinal separation of $D / L=1.47$. The evaluated thrust deduction, $t$, of each case is within the empirical range of 0.13-0.14.

Starting with the twin towed case F1, the drag of B1 is reduced compared to a single towed vehicle. This is due to the bow stagnation of B2 aiding the pressure recovery at the stern of B1. For cases F2 to F6, B2 experiences higher drag than case F1 due to the propeller race at B1. This can be captured by using a propeller race deduction, $\gamma$. Thus the towed drag of the follower vehicle B2 (cases F2 and F4) may be calculated from;-

$$
R_{\mathrm{B} 2 \text { (towed } \mathrm{B} 1)}=(1-\gamma) R_{\mathrm{B} 2 \text { (self-propelled } \mathrm{B} 1)}
$$


Hence, for a self-propelled follower B2 of cases F3, F5 and F6;-

$$
R_{\mathrm{B} 2 \text { (towed B1) }}=(1-\gamma-t) T_{S P, \mathrm{~B} 2 \text { (self-propelled B1) }}
$$

Comparing the results with and without representative torque, it is evident that the momentum source terms which represent propeller thrust are governing the predicted thrust deduction and the propeller race deduction.

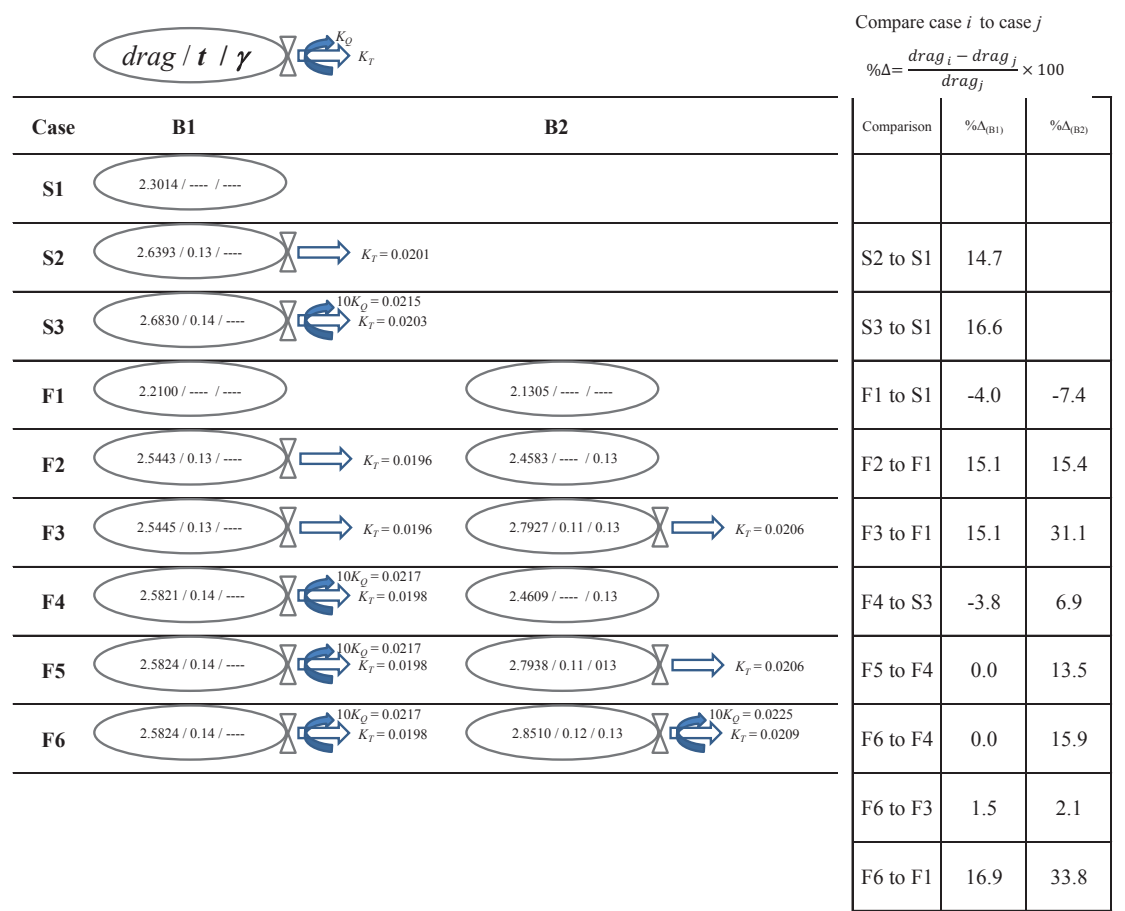

Figure 9: Drag force results and the percentage drag differences in the drafting configuration at $D / L=1.47$, where $d r a g$ represent the towed $\operatorname{drag}(R)$ for a towed case and the self-propelled thrust $\left(T_{S P}\right)$ for any propulsive conditions, $t$ is the thrust deduction and $\gamma$ is defined as the propeller race deduction.

\subsection{Impact of spacing on self-propelled vehicles}

The results of the self-propelled thrust $\left(T_{S P}\right)$, thrust deduction $(t)$, propeller race deduction $(\gamma), K_{T}$ and $10 K_{Q}$ for a pair of self-propelled AUVs over a range of transverse and longitudinal spacings is shown in Figure 10. In a previous study of towed pairs of prolate spheroids, Rattanasiri et al. (2014) defined seven operating regions depending on the changes to individual drag and the total fleet, see Figure 11, where $\% B 1$ and $\% B 2$ is defined as the percentage difference of the individual drag of $\mathrm{B} 1$ and $\mathrm{B} 2$ referenced to a single towed hull drag, respectively. $\% C B$ is defined as the combined drag which considered as a percentage difference of the fleet drag referenced to the sum of two single towed hull drags. Using a similar approach the results for the self-propelled case are presented in Figure 12 Where $\% B 1$ and $\% B 2$ is defined as the percentage difference of the individual selfpropelled drag of B1 and B2 referenced to a single self-propelled resistance $\left(T_{D}\right)$, respectively. $\% C B$ is defined as the combined self-propelled drag which considered as a percentage difference of the fleet drag referenced to the sum of two single self-propelled hull drags. Where $T_{D(\mathrm{~B} 1)}$ and $T_{D(\mathrm{~B} 2)}$ is the self-propelled drag of $\mathrm{B} 1$ and $\mathrm{B} 2$ in fleet, respectively. The sign + and - indicates increasing and decreasing of the towed and self-propelled drag, respectively.

$$
\begin{aligned}
& \% B 1=\frac{T_{D(B 1)}-T_{D(s)}}{T_{D(s)}} \times 100, \\
& \% B 2=\frac{T_{D(B 2)}-T_{D(s)}}{T_{D(s)}} \times 100, \\
& \% C B=\frac{T_{D(\mathrm{~B} 1)}+T_{D(\mathrm{~B} 2)}-2 T_{D(s)}}{2 T_{D(s)}} \times 100
\end{aligned}
$$

By varying the spacing of the pair, the results suggest some energy beneficial configurations exist for an individual but only very small gains are possible for the fleet. However, some configurations lead to a significant increase in the drag of both individual members and the fleet. 


\subsubsection{Parallel region}

The parallel region is where both hulls are parallel to the inflow, nose aligned with zero longitudinal offset $(D / L=0)$, both hulls experience a propeller race deduction due to their close proximity; the propeller generates additional acceleration of the flow between the hulls. A comparison of velocity profile, $V / V_{\infty}$, for the flow past a pair of AUVs at $S / L=0.17$ and $D / L=0$ is shown in Figure 13, In an infinite domain, both hulls are expected to experience an equal propeller race deduction, however, due to the asymmetric finite numerical fluid domain, the tunnel wall results in slightly differing self-propelled thrust, thrust deduction and the propeller race deduction. As the transverse separation increases up to $0.37 \mathrm{~L}$, the increase in accelerated flow due to the action of propeller reduces, resulting in no propeller race deduction. These results and the previous towed studies (Rattanasiri et al., 2014) suggested that the distance of $0.5 \mathrm{~L}$ is required as the minimum transverse separation to exclude body-tobody interaction and the propeller race deduction.

\subsubsection{Echelon region}

With a transverse separation and a limited longitudinal offset within one body length, the configuration is similar to echelon or part of a vee formation. Figure 12 shows that while both hulls experience interaction, the follower B2 experiences a drag reduction while the leader B1 experiences a drag augment, due to the body-to-body interaction Rattanasiri et al. (2014). The comparison of results at $S / L=0.17$ and $D / L=0.57$ configuration as shown in Figure 14 implied that to maintain the speed of the follower in the fleet, the propeller has to operate to pull the AUV backward. As the transverse separation increases, the interactions between the hulls reduce. The information at $S / L=0.17$ and $D / L=0.27$ configuration is not available due to the high interaction between hulls which leads to the difficulty of obtaining the self-propelled follower.

\subsubsection{Push region}

The push region is where the nose of follower is positioned close to the trailing edge of the leading AUV. The results show a significant decrease in the self-propelled drag of the leader, similar to the results for the towed case. A comparison of velocity profiles is shown in Figure 15 Vessels placed directly downstream of a propeller experience a significant propeller race deduction. A small transverse separation is sufficient to place the follower to one side of the propeller race where it experiences minimal propeller race deduction.

\subsubsection{Drafting region}

By placing a towed B2 directly behind a towed B1 for $D / L>1.37$, both individual AUVs and the fleet experience drag reduction (Rattanasiri et al., 2014), however this benefit has been removed by the action of the propeller for the self-propelled cases. Being placed in propeller race, the follower experiences a propeller race deduction of $\gamma=0.13$. A comparison of velocity profiles is shown in Figure 16 .

\subsubsection{No propeller race interaction zone}

From Figure 10, there is minimal effect of propeller race deduction on the leader B1 or follower B2. A comparison of the velocity profile of a pair of AUVs at $S / L=0.17$ and $D / L=1.47$ configuration, Figure 17, shows a very small accelerated flow regime by propellers from leader B1 interact the flow regime around the follower B2. It could be concluded that the bigger the transverse separation and longitudinal offset, the smaller the accelerated flow regime between hulls. 


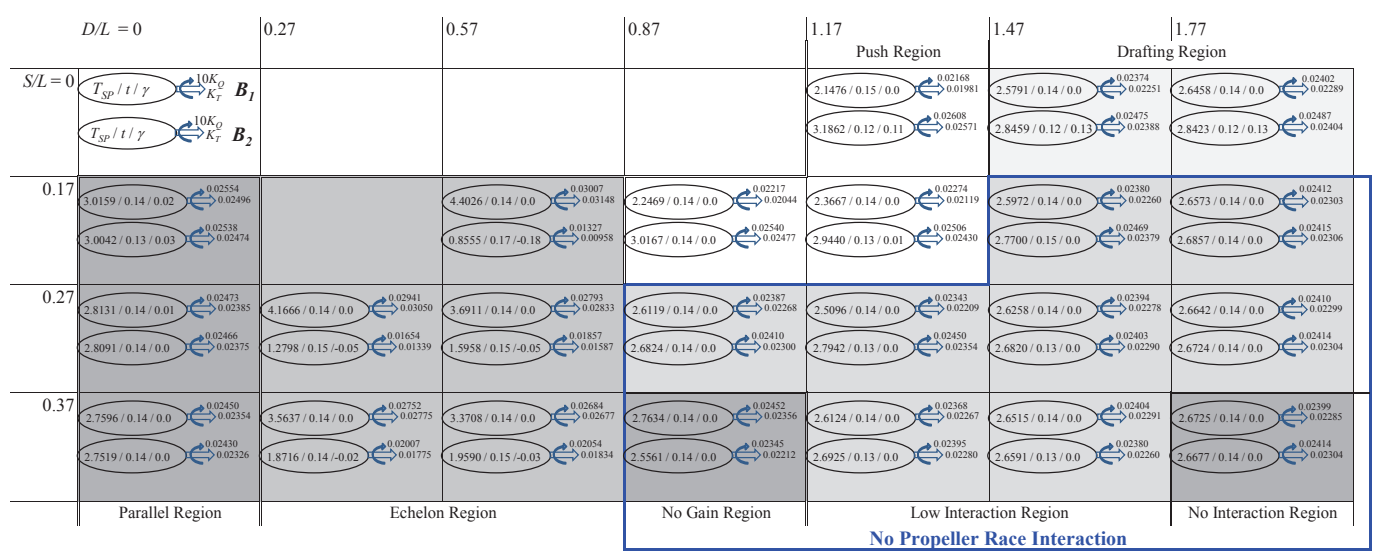

Figure 10: The results of individual self-propelled thrust $\left(T_{S P}\right)$, thrust deduction $(t)$, propeller race deduction $(\gamma), K_{T}$ and $10 K_{Q}$ at various spacings

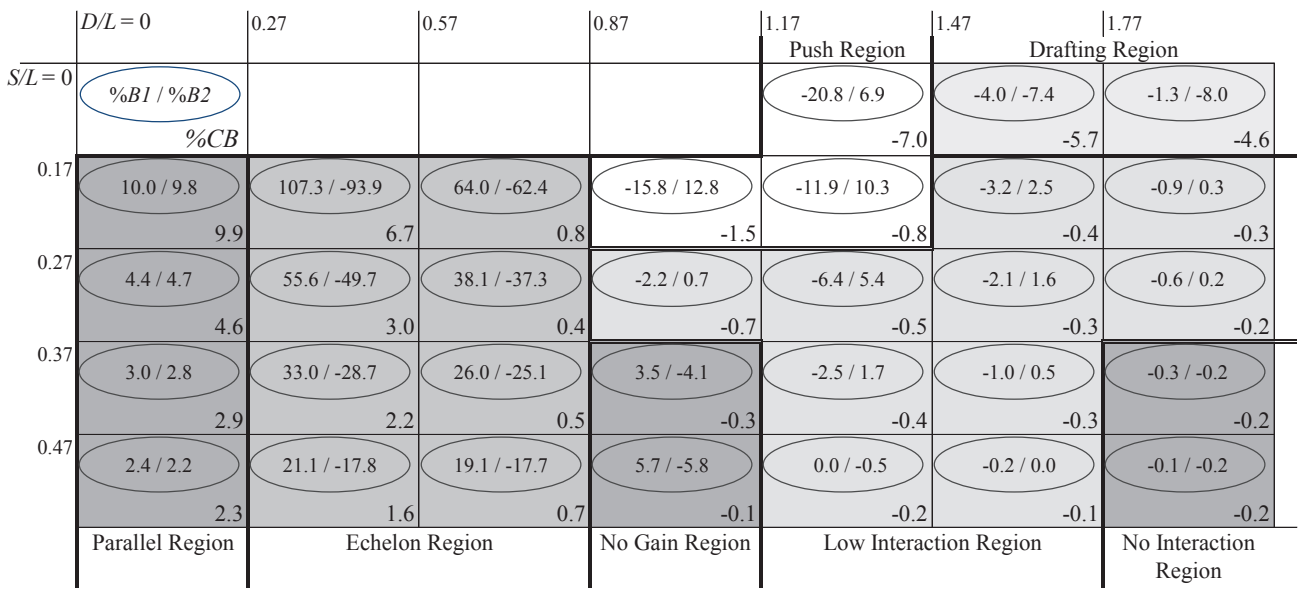

Figure 11: The effect of towed twin hulls' spacing on individual drags and combined drag of $\mathrm{B} 1$ and $\mathrm{B} 2$ at $R e=3.2 \times 10^{6}$ Rattanasiri et al. 2014)

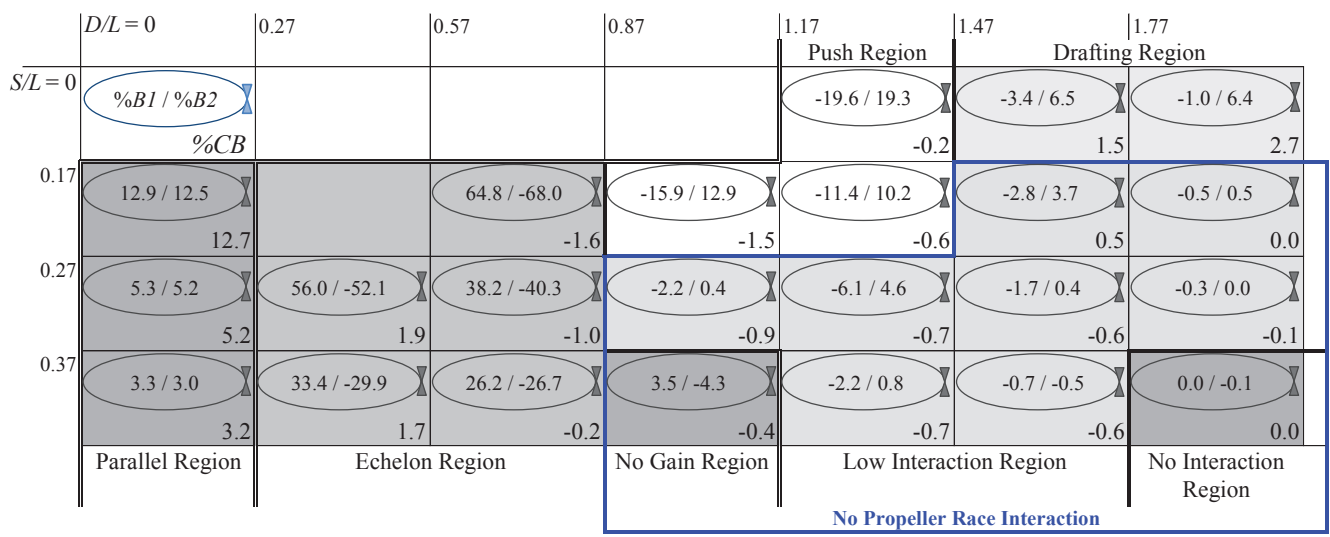

Figure 12: The effect of twin hulls' spacing on individual self-propelled thrust and combined drag of B1 and B2 


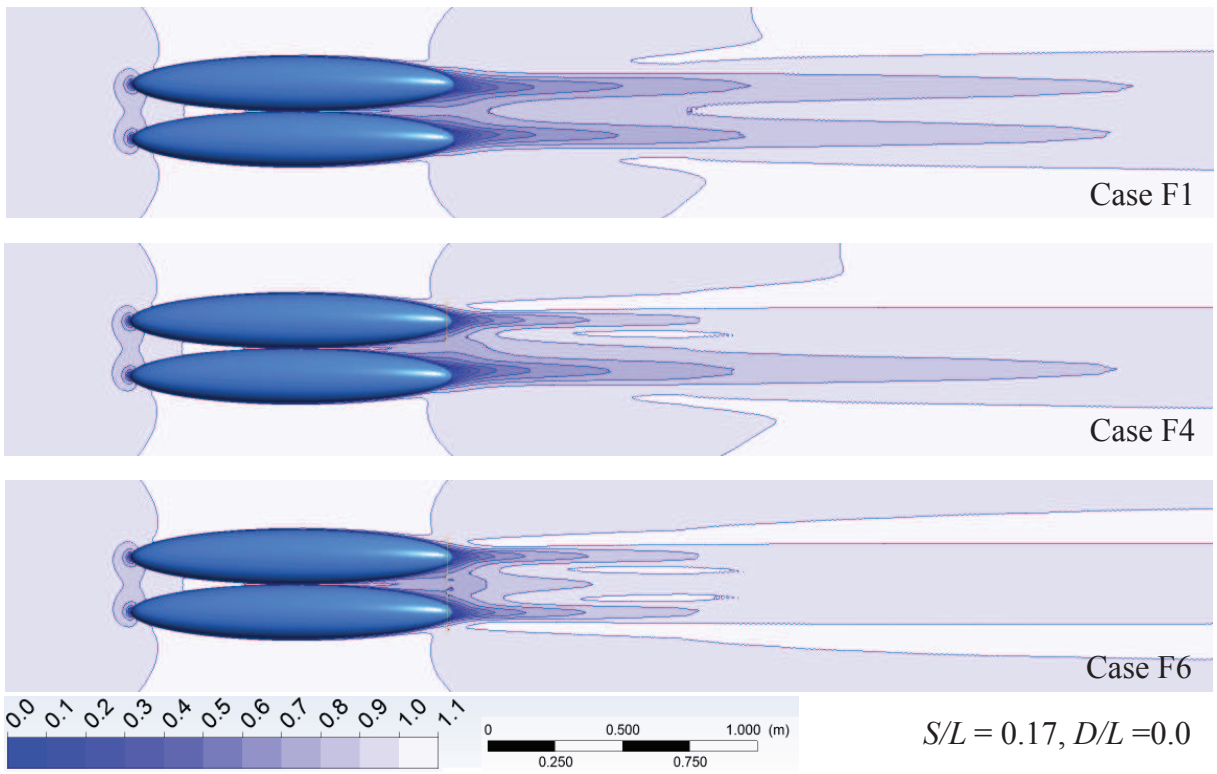

Figure 13: Comparison of velocity profile $V / V_{\infty}$ of fluid inflow past a pair of AUVs at $S / L=0.17$ and $D / L=0.0$ configuration; (Top) Case F1: towed B1 and towed B2, (Middle) Case F4: self-propelled B1 and towed B2 (bottom) Case F6: self-propelled B1 and self-propelled B2.

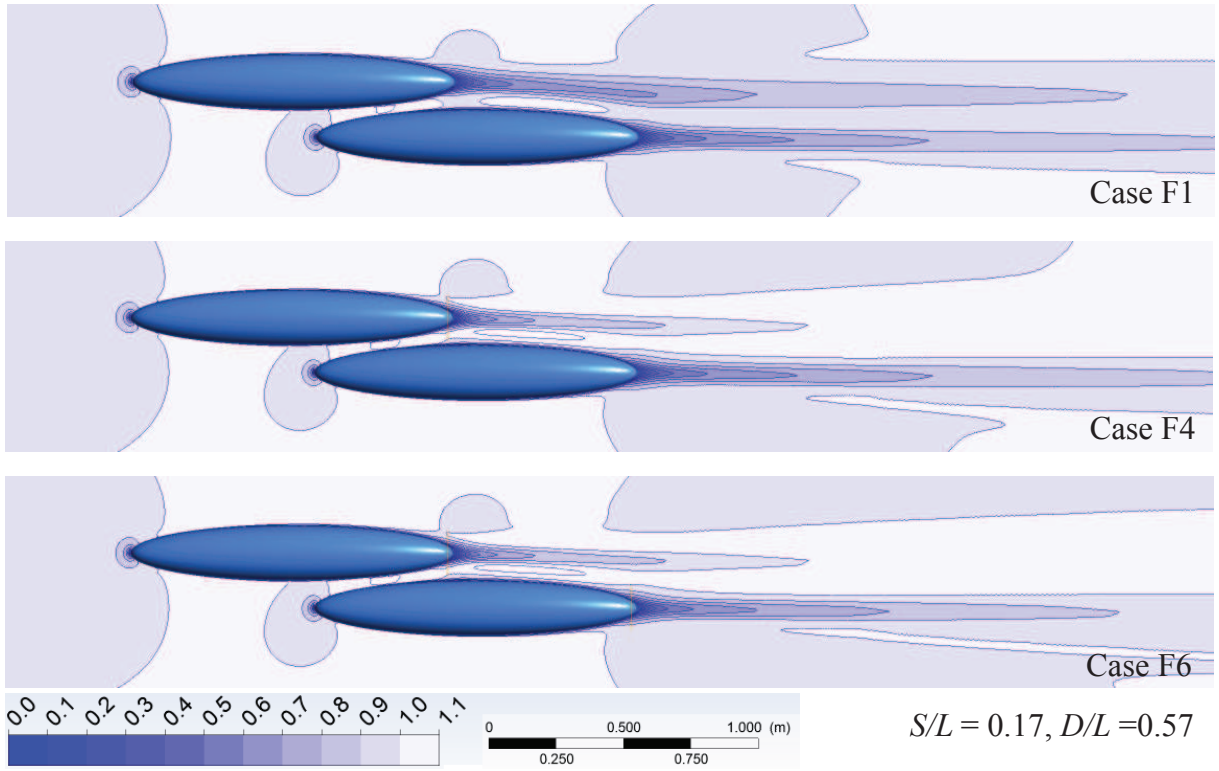

Figure 14: Comparison of velocity profile $V / V_{\infty}$ of fluid inflow past a pair of AUVs at $S / L=0.17$ and $D / L=0.57$ configuration; (Top) Case F1: towed B1 and towed B2, (Middle) Case F4: self-propelled B1 and towed B2 (bottom) Case F6: self-propelled B1 and self-propelled B2. 


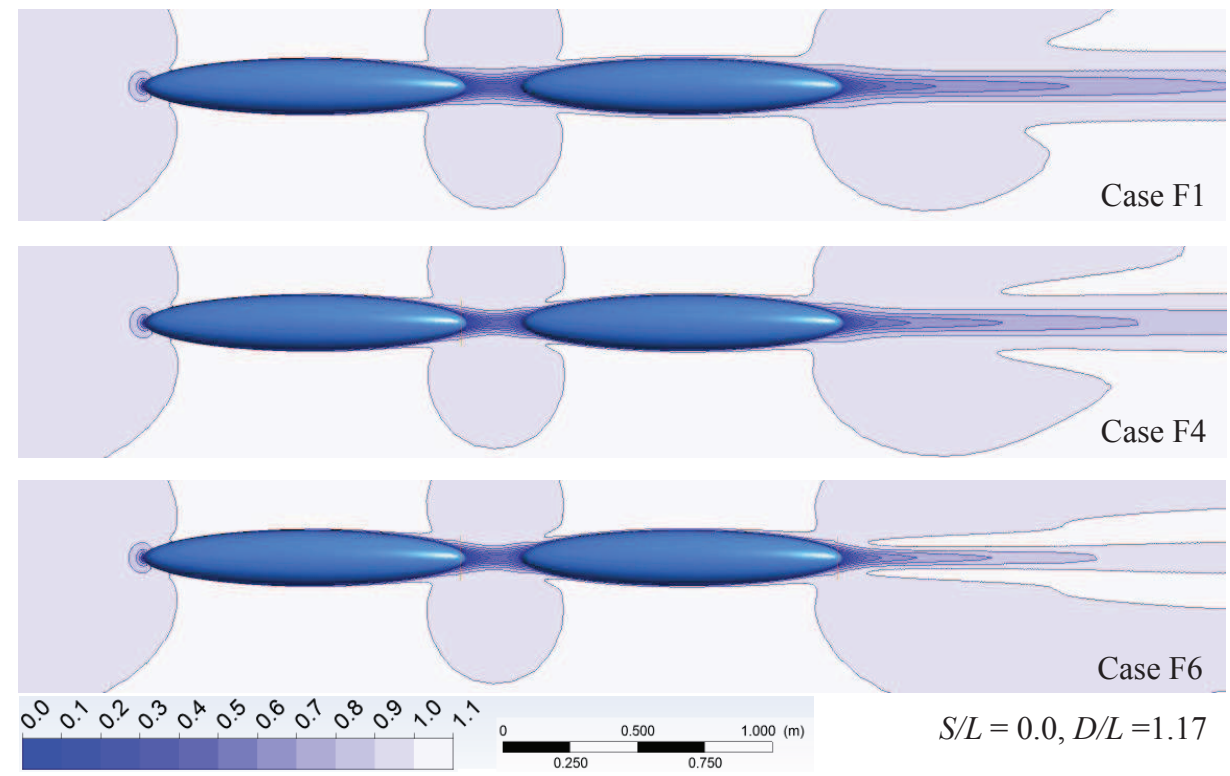

Figure 15: Comparison of velocity profile $V / V_{\infty}$ of fluid inflow past a pair of AUVs at $S / L=0.0$ and $D / L=1.17$ configuration; (Top) Case F1: towed B1 and towed B2, (Middle) Case F4: self-propelled B1 and towed B2 (bottom) Case F6: self-propelled B1 and self-propelled B2.

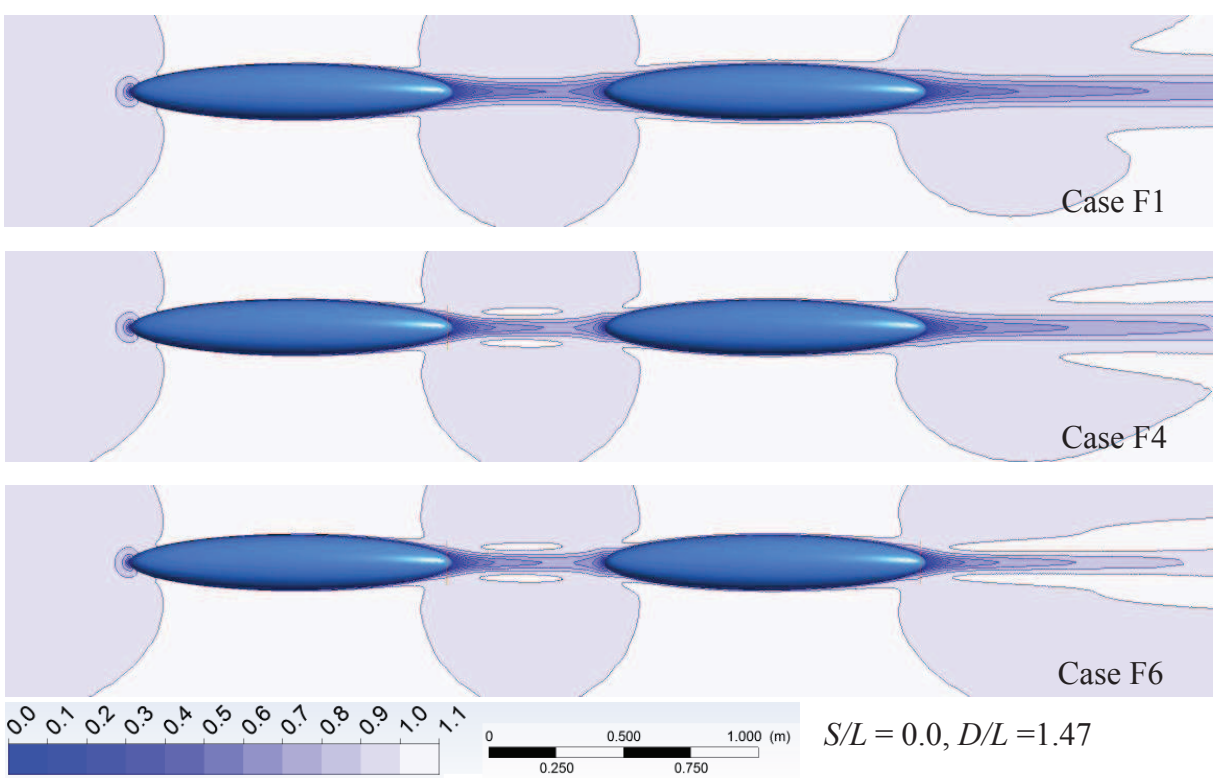

Figure 16: Comparison of velocity profile $V / V_{\infty}$ of fluid inflow past a pair of AUVs at $S / L=0.0$ and $D / L=1.47$ configuration; (Top) Case F1: towed B1 and towed B2, (Middle) Case F4: self-propelled B1 and towed B2 (bottom) Case F6: self-propelled B1 and self-propelled B2. 


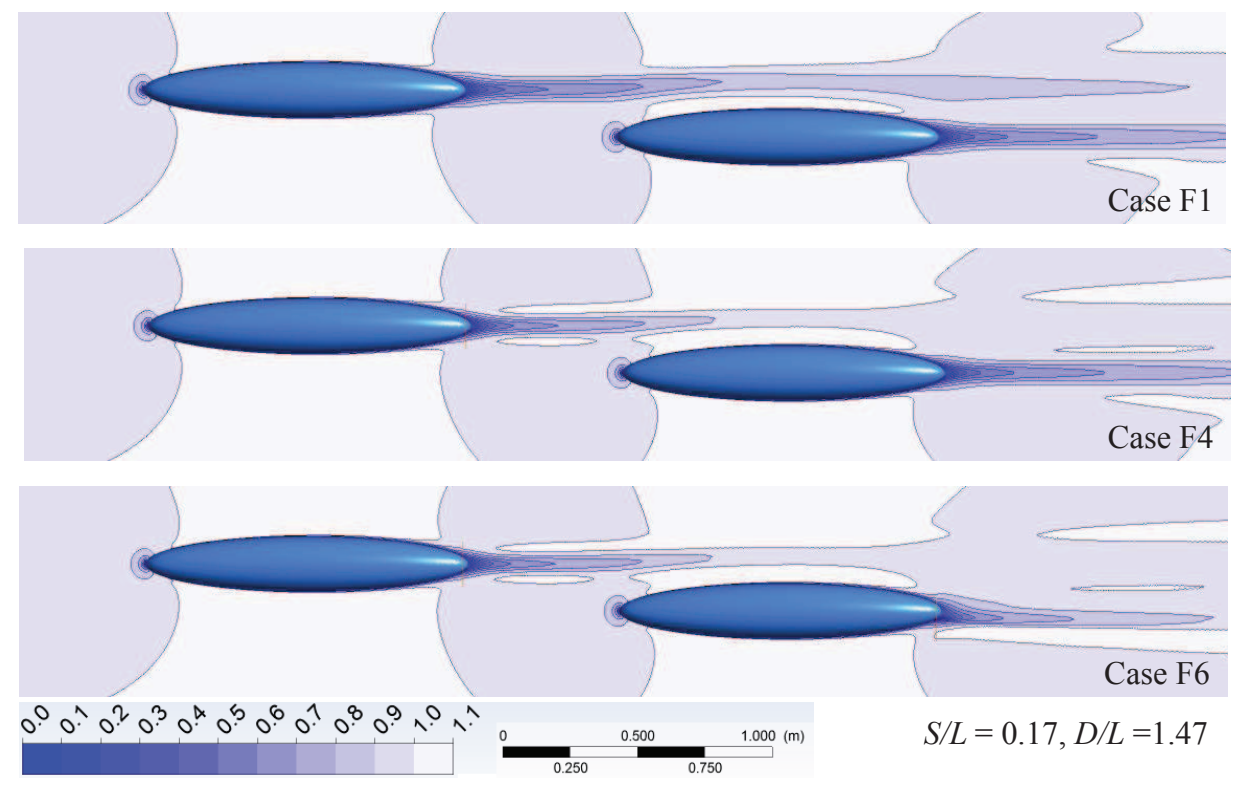

Figure 17: Comparison of velocity profile $V / V_{\infty}$ of fluid inflow past a pair of AUVs at $S / L=0.17$ and $D / L=1.47$ configuration; (Top) Case F1: towed B1 and towed B2, (Middle) Case F4: self-propelled B1 and towed B2 (bottom) Case F6: self-propelled B1 and self-propelled B2.

\subsection{Twin vehicles at various drafting and parallel configurations}

Thus we can conclude that the parallel, push and the drafting regions experience the greatest interactions, these will be examined in more detail in this section.

\subsubsection{Parallel configurations}

Figure 18 illustrates the influence of the transverse separation in the parallel configuration on the components of drag. Implementing the propeller on both hulls increases the drag on both hulls. For case F1, at $S / L=0.17$, the total drag of both towed vehicles is increased by $10 \%$, it is due to a change in the pressure drag rather than a skin friction drag. As the separation increases, the drag of both hulls tends towards the drag of a single free stream towed resistance.

For cases F2, the total drag of self-propelled B1 is increased by $15 \%$ compared to the towed B1 (F1) and then tends toward the single self-propelled thrust as the separation increases. From Figure $18 \mathrm{~b}$ and $18 \mathrm{c}$, at the separation within $0.27 L$, the propeller race deduction results from the self-propelled B1 is driven the pressure drag of towed B2 to be increased by $15 \%$ when compared to the towed B2 (F1), consequently increase a $4 \%$ of its total drag.

For case F3, at $S / L=0.17$, the self-propelled B1 (F3) experiences a $4 \%$ drag augment compared to that of F2. This suggests that the propeller race deduction from both self-propelled AUVs interacts with each other, subsequently disturbing the pressure distribution around the hulls. For $S / L>0.30$, the drag of both self-propelled vehicles tends towards the free stream thrust requirements.

\subsubsection{Drafting configurations}

Figure 19 illustrates the influence of the longitudinal offset in the drafting configuration on the components of drag. Starting with case $\mathrm{F} 1$, at $D / L=1.17$, the total drag of B1 is increased by $8 \%$ whilst the total drag of B2 is reduced by $21 \%$ (Figure 19a). As the longitudinal offset increases, the drag of both towed hulls tends towards the free stream drag as wake recovery occurs. This hydrodynamic behaviour is similar to cars in a convoy with a slipstream at $S / L>1.5$ (Hucho and Ahmed, 1998). This goes some-way to explain the energy benefit of cycling and swimming in the slipstream (Kyle, 1979; Silva et al.,2008). According to Figure19b and19c the discrepancy of the total drag of both hulls is driven by a change to the pressure drag. Significantly, a change to the skin friction drag of B2 occurs when placed directly behind towed B1, this dominates the B2's drag reduction. Then at $D / L=$ 4.47 , the total drag of both hulls tends towards the single free stream towed resistance.

For case $\mathrm{F} 2$, at $1.17 \leq D / L \leq 4.47$, the total drag of self-propelled $\mathrm{B} 1$ is increased by $12 \%$ compared to that of towed B1 (F1). The drag of self-propelled B1 tends towards the single vehicle self-propelled thrust as the offset 
increases. Considering Figure $19 \mathrm{~b}$ and $19 \mathrm{c}$, at $D / L=1.17$, the drag of $\mathrm{B} 2$ is increased by $12 \%$ compared to that of towed B2 (F1), this is due to an addition to the skin friction drag results from a propeller race deduction. As the offset increases, the extra skin friction drag is reduced which results in a decrease of the total drag augment towards the single towed resistance at $D / L>5.0$.

For case F3, the drag of self-propelled B1 (F3) shows the same results as that of case F2. Apparently, placing either a towed B2 (F2) or self-propelled B2 (F3) directly behind the self-propelled B1 has no impact to the B1's drag. At $D / L=1.17$, the drag of the self-propelled $\mathrm{B} 2(\mathrm{~F} 3)$ is increased by $18 \%$ compared to the towed $\mathrm{B} 2(\mathrm{~F} 2)$. The drag of self-propelled B2 (F3) is then reduced towards the free stream thrust when the offset increases. Figure $19 \mathrm{~b}$ and $19 \mathrm{c}$ show that a change of the total drag augment is influenced by the pressure drag rather than the skin friction drag.

For these drafting cases, in general, for vehicles following a self-propelled leader within 5.0L, the skin friction drag of the follower is increased by the propeller race deduction, consequently, a rise in the total drag. For longitudinal offsets $D / L>5.0$, the drag of both B1 and B2 tend towards the single free stream value, which are at a towed resistance and a self-propelled thrust for the towed vehicle and self-propelled vehicle, respectively.

For all drafting and parallel cases, with both vehicles in close proximity, significant change in the pressure drag dominates an increment in the total drag. The propeller race deduction influences a significant change in the skin friction drag of any vehicle placed directly behind a self-propelled vehicle. On the other hand, in very close proximity in the parallel configuration, the propeller race drives a $25 \%$ increase in the pressure drag for both vehicles; it is evident that a change of the skin friction drag has a minimal change of less than $1 \%$.

\section{Conclusion}

This paper investigates the influence of the propeller race on upstream and downstream self-propelled AUVs. Initially simulations of a self-propelled hull are performed, utilising body force model to replicate the impact of the propeller by modelling the momentum source terms. This is then extended to consider a fleet of two selfpropelled vehicles operating at a range of longitudinal offset and transverse separation.

The results highlight that operation in close proximity to another self-propelled vessel has a significant impact of both the flow around the hull and drag experienced by the vehicle. A propeller race deduction is proposed to account for the increase in vehicle drag due to the propulsors of other vehicles. The propeller race deduction is dependent on both longitudinal and transverse separation.

The self-propelled results using a virtual propeller show no significant propulsive energy benefit to the total fleet energy budget. In-line operation which has previously been shown to be beneficial for towed vehicles is shown to give no or minimal benefit to self-propelled vehicles due to the upstream propeller re-energising the wake. An echelon configuration does allow a transfer of drag from the follower to the leader, but would require additional course keeping due to the hydrodynamic moment induced on the vehicle. A parallel configuration results in an increased propulsion cost for both vehicles. However, based on this numerical information, operators can determine the optimal configurations in transverse separation and longitudinal offset based on energy considerations. However, this information is based on a homogeneous fleet of torpedo style vessels, by adopting a heterogeneous fleet or a non-conventional body shape it may be possible to reduce the resistance of following vessels if they are designed such that the follower(s) operate in the wake of a leading vehicle but outside of its propeller race.

From a vehicle or mission design perspective, it is important to correctly understand the true propulsive energy budget of the vehicle and its impact on both range and endurance. This study highlights the importance of considering both thrust deduction and any propeller race deductions when calculating the propulsive power consumption of an individual or fleet of vehicles.

\section{Acknowledgment}

The authors acknowledge the use of the IRIDIS High Performance Computing Facility, and associated support services at the University of Southampton, in the completion of this work. The PhD studentship of Rattanasiri was financed by the Royal Thai Government. 


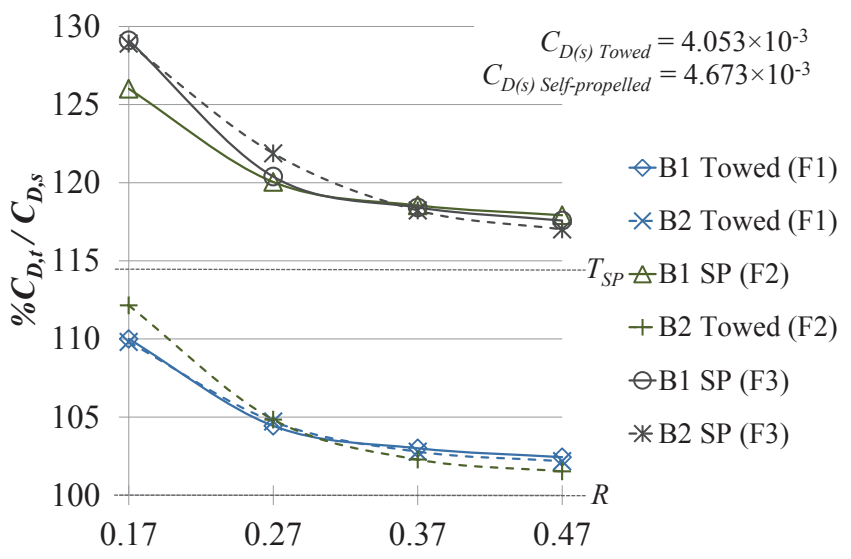

(a) Total drag coefficient

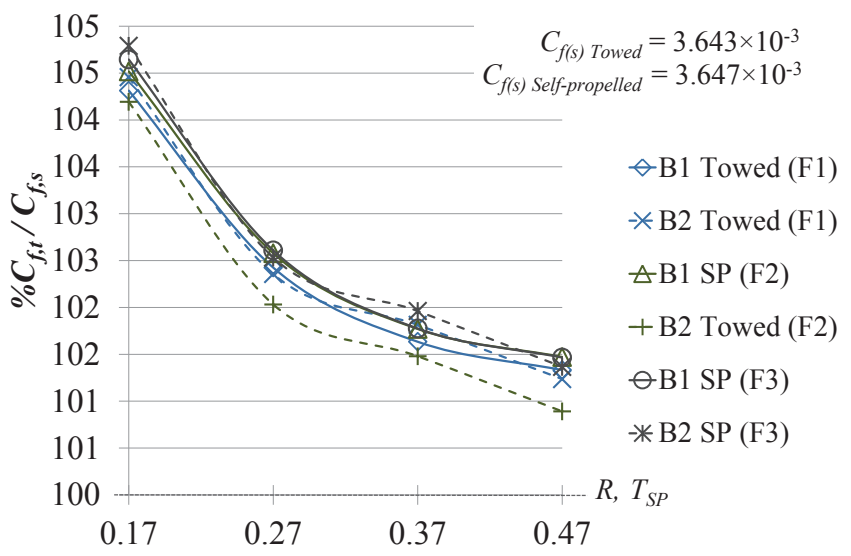

(b) Skin friction drag coefficient

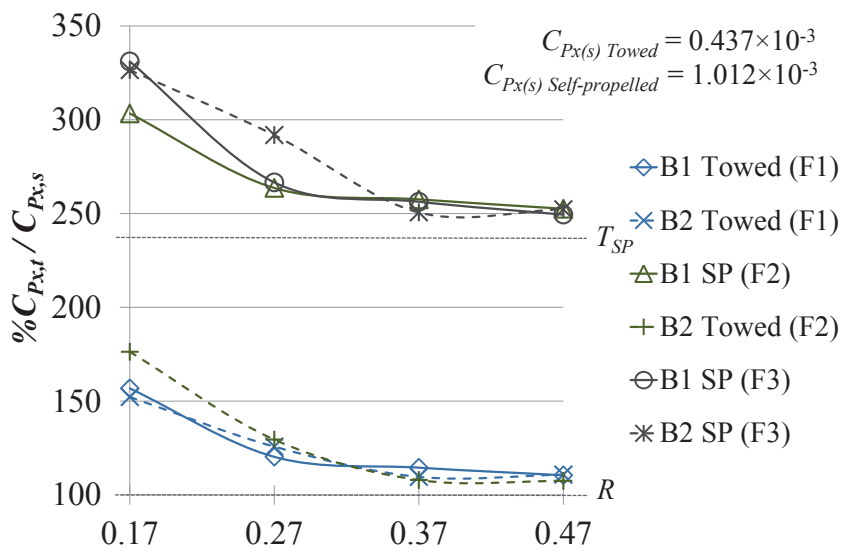

(c) Pressure drag coefficient 


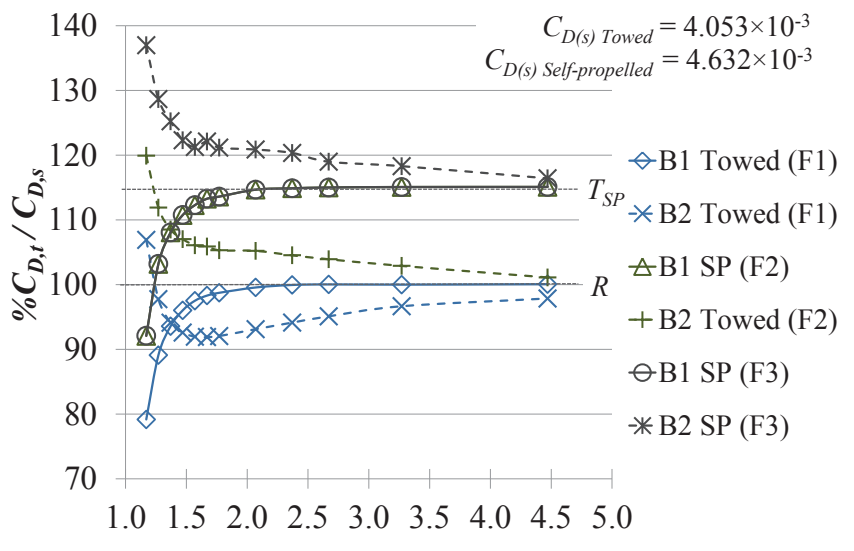

(a) Total drag coefficient

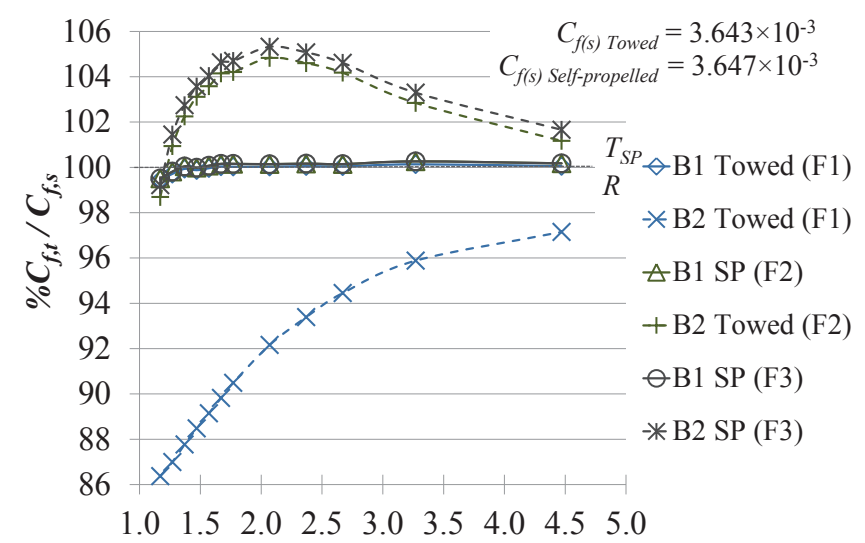

(b) Skin friction drag coefficient

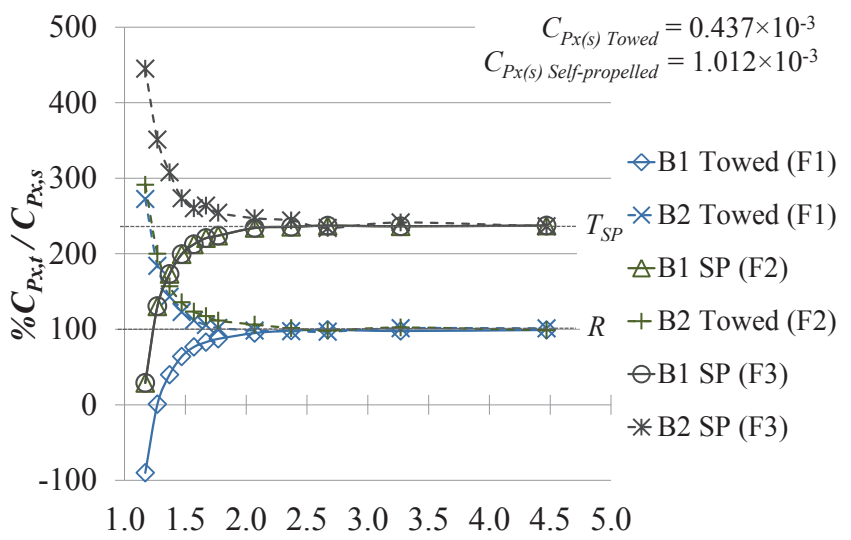

(c) Pressure drag coefficient 


\section{References}

Ageev, M., 2000. Solar and wave powered AUV concept., in: Underwater Technology, 2000. UT 00. Proceedings of the 2000 International Symposium, pp. 136-139. doi:10.1109/UT .2000.852530.

Ageev, M.D., 1995. An analyses of long-range AUV, powered by solar energy., in: OCEAN'95 Conference, San Diego. IEEE, pp. 809-813.

Alers, P., 1981. Trade-off studies for the unmanned free swimming submersible. Oceans 1981 Conference Notes , 113-117.

Alexander, R.M., 2004. Hitching a lift hydrodynamically - in swimming, flying and cycling. Journal of Biology 3. doi:http://dx.doi.org/10.1186/jbiol5.

Andersson, M., Wallander, J., 2003. Kin selection and reciprocity in flight formation? Behavioral Ecology 15, $158-162$.

ANSYS, 2010. ANSYS CFX, Release 12.1. ANSYS. Pennsylvania.

Bingham, D., Drake, T., Hill, A., Lott, R., 2002. The application of autonomous underwater vehicle (AUV) technology in the oil industry vision and experiences., in: In FIX XXII International Congress Washington, D.C. USA, pp. 1-13.

Burcher, R., Rydill, L., 1994. Concepts in submarine design. Cambridge: Cambridge University Press.

Caccia, M., 2006. Autonomous surface craft: prototypes and basic research issues, in: 14th Mediterranean Conference on Control and Automation, pp. 1-6.

Furlong, M.E., McPhail, S.D., Stevenson, P., 2007. A concept design for an ultra-long-range survey class AUV., in: Oceans '07, Aberdeen, Scotland, 19-21 June.

Goldstein, S. (Ed.), 1929. On the vortex theory of screw propellers.. Proc. of the Royal Society (A) 123, 440.

Griffiths, G., 2003. Technology and alpplications of Autonomous Underwater Vehicles.. volume 2 of Ocean science and technology. CRC Press.

Hanrahan, B., Juanes, F., 2001. Estimating the number of fish in atlantic bluefin tuna schools using models derived from captive school observations. Fishery Bulletin 99(3), 420-431.

Hoerner, S.F., 1965. Fluid-dynamic drag: practical information on aerodynamic drag and hydrodynamic resistance. (pubished by the author).

Horgan, J., Toal, D., 2006. Review of machine vision applications in unmanned underwater vehicles, in: 9th International Conference on Control, Automation, Robotics and Vision, pp. 1-6.

Hough, G., Ordway, D., 1965. The generalised actuator disc. Developments in Theor. and Appl. Mech. 2, 317336.

Hucho, W.H., Ahmed, S.R., 1998. Aerodynamics of road vehicles : from fluid mechanics to vehicle engineering. Warrendale, Pa. : Society of Automotive Engineers.

Huggins, A., Packwood, A.R., 1994. The optimum dimensions for a long-range, autonomous, deep-driving, underwater vehicle for oceanographic research. Ocean Engineering 21, 45-56.

Husaini, M., Samad, Z., Arshad, M.R., 2009. CFD simulation cooperative AUV motion. Indian Journal of marine Sciences 38(3), 346-351.

Jagadeesh, P., Murali, M., Idichandy, V.G., 2009. Experimental investigation of hydrodynamic force coefficients over AUV hull form. Journal of Ocean Engineering 36, 113-118.

Karim, M.M., Rahman, M.M., Alim, M.A., 2009. Computation of turbulent viscous flow around submarine hull using unstructured grid. .

Kyle, C.R., 1979. Reduction of wind resistance and power output of recing cyclists and runners traveling in group. Ergonomics 22, 387-397. 
Larsson, L., Baba, E., 1996. Advances in marine hydrodynamics. Computational Mechanics Publications. volume 5. chapter Ship resistance and flow computations. pp. 1-75. (Chapter: Ship resistance and flow computations).

McPhail, S., 2009. Autosub6000: A deep driving long range AUV. Journal of Bionic Engineering 6, 55-62.

Menter, F.R., 1994. Two-equation eddy-viscosity turbulence models for engineering applications. AIAA Journal $32(8), 1598-1605$.

Molland, A.F., Utama, I.K.A.P., 1997. Wind tunnel investigation of a pair of ellipsoids in close proximity. Technical Report 98. Ship Science, University of Southampton.

Molland, A.F., Utama, I.K.A.P., 2002. Experimental and numerical investigations of a pair a ellipsoids in close proximity., in: Proceedings of the Institution of Mechanical engineers, Part M: Journal of Engineering for the Maritime Environment, pp. 107-115.

Parsons, J.S., 1972. The optimum shaping of axisymmetric bodies for minimum drag in incompressible flow. Ph.D. thesis. School of Mechanical Engineering, Purdue University, Lafayette, Ind.

Parsons, J.S., Goodson, R.E., Goldschmied, F.R., 1974. Shaping of axisymmetric bodies for minimum drag in incompressible flow. Journal of Hydronautics 8, 100-107.

Partridge, B.L., Johansson, J., Kalish, J., 1983. The structure of schools of giant bluefin tuna in cape cad bay. Environmental Biology of Fishes 9, 253-262.

Paterson, E.G., Wilson, R.V., Stern, F., 2003. General purpose parallel unsteady RANS ship hydrodynamics code CFDSHIP-IOWA. IIHR Rep.. Univ. of Iowa.

Phillips, A., Turnock, S., Furlong, M., 2008. Comparisons of CFD simulations and in-service data for the self propelled performance of an Autonomous Underwater Vehicle., in: 27th Symposium of Naval Hydrodynamics, Seoul, Korea, 05 - 10 Oct 2008.

Phillips, A., Turnock, S.R., Furlong, M., 2010a. Accurate capture of propeller-rudder interaction using a coupled blade element momentum-rans approach. Ship Technology Research. Schiffstechnik. 57.

Phillips, A.B., 2009. Cost effective hydrodynamic concept design of autonomous underwater vehicle. Ph.D. thesis. School of Engineering Sciences, University of Southampton, UK.

Phillips, A.B., Blake, J., Smith, B., Boyd, S., Griffiths, G., 2012. Nature in engineering for monitoring the oceans (nemo): an isopycnal soft bodied approach for deep diving autonomous underwater vehicles., in: In, Autonomous Underwater Vehicles (AUV), 2012 IEEE/OES. Piscataway NJ, USA. volume 224, (4), pp. 267268.

Phillips, A.B., Furlong, M., Turnock, S.R., 2007. The use of computational fluid dynamics to assess the hull resistance of concept autonomous underwater vehicles., in: OCEANS 2007 - Europe. Richardson TX, USA, Institute of Electrical and Electronics Engineers.

Phillips, A.B., Turnock, S.R., Furlong, M., 2010b. Influence of turbulence closure models on the vortical flow field around a submarine body undergoing steady drift. Journal of Marine Science and Technology 15(3), 201-217.

Phillips, A.B., Turnock, S.R., Furlong, M., 2010c. The use of computational fluid dynamics to aid cost-effective hydrodynamic design of autonomous underwater vehicles., in: Proceedings of the Institution of Mechanical Engineers, Part M: Journal of Engineering for the Maritime Environment, pp. 239-254.

Phillips, A.B., Turnock, S.R., Furlong, M.E., 2009. Evaluation of manoeuvring coefficients of a self-propelled ship using a blade element momentum propeller model coupled to a reynolds averaged navier stokes flow solver. Ocean Engineering 36, 1217-1225.

Rattanasiri, P., Wilson, P.A., Phillips, A.B., 2014. Numerical investigation of a fleets of towed auvs. Ocean Engineering 80, 20-35.

Sarkar, T., Sayer, P.G., Fraser, S.M., 1997. A study of autonomous underwater vehicle hull forms using computational fluid dynamics. International journal for Numerical Methods in Fluids 25, 1301-1313. 
Silva, A.J., Rouboa, A., Moreira, A., Reis, V.M., Alves, F., Vilas-Boas, J.P., Marinho, D.A., 2008. Analysis of drafting effects in swimming using computational fluid dynamics. Journal of Sports Science and Medicine 7 , 60-66.

Smallwood, D., Whitcomb, L., 2004. Model-based dynamic positioning of underwater robotic vehicles: theory and experiment. IEEE Journal of Oceanic Engineering 29 No. 1, 169-186.

Stern, F., Kim, H.T., Cheng, H.C., 1988. A viscous-flow approach to the computation of of propeller-hull interaction. Journal Ship Research 32, 246-262.

Stevenson, P., Furlong, M., Dormer, D., 2007. AUV shapes - combining the practical and hydrodynamic considerations., in: OCEANS 2007 - Europe.

Tripp, S.T., 2006. Autonomous underwater vehicles (AUVs): A look at coast guard needs to close performance gaps and enchance current mission performance. Technical Report. Technical report, US Coast Guard Research and Development Center.

Turnock, S.R., Phillips, A.B., Furlong, M., 2008. URANS Simulations of statics drift and dynamic manoeuvres of the KVLCC2 tanker., in: In SIMMAN Int. Manoeuvring Workshop, Copenhagen.

Weihs, D., 2004. The hydrodynamics of dolphin drafting. Journal of Biology 3:8.

Woods, J.D., 1997. The EuroGOOS strategy. Elsevier Oceanography Series 62, 19-35. 


\section{Nomenclature}

\begin{tabular}{|c|c|}
\hline $1+k$ & The form factor of a single spheroid \\
\hline $1+\beta k$ & The form factor of twin spheroids \\
\hline$A_{w}$ & Wetted surface area $\left(\mathrm{m}^{2}\right)$ \\
\hline $\mathrm{B} 1$ and $\mathrm{B} 2$ & Leader spheroid and follower spheroid \\
\hline$\% B 1$ and $\% B 2$ & Individual drag of $\mathrm{B} 1$ and $\mathrm{B} 2$ referred to a single hull drag \\
\hline$\% C B$ & Combined drag refer to sum of two single hull drags \\
\hline$C_{F}$ & Skin friction drag coefficient, $\frac{\text { Skin friction drag }}{0.5 \rho V^{2}}$ \\
\hline$C_{P x}$ & Pressure drag coefficient, $\frac{\text { Pressure drag }}{0.5 \rho V^{2}}$ \\
\hline$C_{t h}$ and $K_{T}$ & Thrust coefficient \\
\hline$d_{m}$ & Maximum diameter of the body of revolution $(\mathrm{m})$ \\
\hline$D$ & Longitudinal offset (m) \\
\hline$D / L$ & Non-dimensional longitudinal offset \\
\hline$d_{h}$ & Maximum hull diameter $(\mathrm{m})$ \\
\hline$F_{i}$ & The momentum source terms $\left(\bar{F}_{X}, \bar{F}_{Y}, \bar{F}_{Z}\right)$ \\
\hline$F \bar{b}_{x}$ & Non-dimensional axial momentum source term \\
\hline$\overline{F b}_{\theta}$ & Non-dimensional tangential momentum source term \\
\hline$F \bar{b}_{r}$ & Non-dimensional radial momentum source term \\
\hline$J$ & Advance coefficient \\
\hline$K_{Q}$ & Torque coefficient \\
\hline$n$ & Revolutions per second of propeller $\left(\mathrm{s}^{-1}\right)$ \\
\hline$S / L$ & Transverse separation \\
\hline$t$ & Thrust deduction \\
\hline$T_{D}$ & The self-propelled drag $(\mathrm{N})$ \\
\hline$T_{D(\mathrm{~B} 1)}$ and $T_{D(\mathrm{~B} 2)}$ & Self-propelled drag of B1 and B2 in fleet \\
\hline$T_{S P}$ & The require thrust $(\mathrm{N})$ \\
\hline$L$ & Length of the body from nose to tail $(\mathrm{m})$ \\
\hline$R$ & Towed drag $(\mathrm{N})$ \\
\hline$R_{(s)}$ & towed drag of a single hull \\
\hline $\operatorname{Re}$ & Length Reynolds number, $\frac{V L}{v}$ \\
\hline$R_{p}$ and $R_{h}$ & Radius of propeller and hub (m) \\
\hline$r_{p}$ & Local propeller radius (m) \\
\hline$V$ & Vehicle speed (m/s) \\
\hline$V_{a}$ & Advance speed $(\mathrm{m} / \mathrm{s})$ \\
\hline$U_{i}$ & Cartesian mean velocity components $\left(\overline{U_{x}}, \overline{U_{y}}, \overline{U_{z}}\right)$ \\
\hline$w_{t}$ & Wake fraction \\
\hline $\bar{w}_{t}$ & Mean wake fraction over propeller disc \\
\hline$x_{i}$ & Represents Cartesian co-ordinates $(X, Y, Z)(\mathrm{m})$ \\
\hline$v$ & Fluid kinematic viscosity, $\mu / \rho\left(\mathrm{m}^{2} / \mathrm{s}\right)$ \\
\hline$\rho$ & Fluid density $\left(\mathrm{kg} / \mathrm{m}^{3}\right)$ \\
\hline$\mu$ & Fluid dynamic viscosity (kg/m.s) \\
\hline$k$ & Fluid turbulent kinetic energy $\left(\mathrm{m}^{2} / \mathrm{s}^{2}\right)$ \\
\hline$\epsilon$ & Rate of dissipation of turbulent energy $\left(\mathrm{m}^{2} \mathrm{~s}^{-3}\right)$ \\
\hline$\widetilde{v}$ & Viscosity like variable \\
\hline$\gamma$ & The propeller race deduction \\
\hline$\Delta$ & The difference between drags \\
\hline
\end{tabular}

